\title{
Externally Applied Cyclic Strain Regulates Localization of Focal Contact Components in Cultured Smooth Muscle Cells
}

\author{
James J. Cunningham, ${ }^{1}{ }^{\text {Jennifer J. Linderman, }}{ }^{1}$ and DAVID J. MoOneY ${ }^{1,2,3}$ \\ ${ }^{1}$ Department of Chemical Engineering, ${ }^{2}$ Department of Biomedical Engineering, and ${ }^{3}$ Department of Biologic and Materials Sciences,
} The University of Michigan, Ann Arbor, MI 48109

(Received 16 July 2001; accepted 31 May 2002)

\begin{abstract}
Mechanical signals are critical regulators of cellular gene expression, yet little is understood of the mechanism whereby cells sense mechanical forces. In this study we have tested the hypothesis that mechanical strain applied to populations of cells via their adhesion substrate rapidly alters the cellular distribution of focal contact proteins. Focal contactassociated components (vinculin, $\alpha$-actinin, paxillin) were assayed by immunofluorescence microscopy and quantitative western blotting. Application of a single step increase in strain in multiple experiments caused overall a small change in focal contact-associated vinculin. In contrast, cyclic strain induced a large and very reproducible increase in detergent-insoluble vinculin (52\% relative to static) after just $1 \mathrm{~min}$ of strain. Insoluble paxillin was transiently enriched with a similar time course, whereas insoluble $\alpha$-actinin did not change significantly in response to cyclic strain. Rhodamine-labeled chicken vinculin added to permeabilized cells preferentially localized to focal contacts in response to cyclic strain, but not a single step increase in strain. These findings establish that insoluble levels of focal contact components are altered rapidly following application of an appropriate number of mechanical perturbations, and suggest that at least one component of the mechanism does not involve soluble intermediates. (C) 2002 Biomedical Engineering Society. [DOI: 10.1114/1.1500408]
\end{abstract}

Keywords-Vinculin, Paxillin, Mechanical strain, Fluorescence labeling.

\section{INTRODUCTION}

Mechanical strain plays a critical role in the development and continuous remodeling of numerous tissues, such as blood vessels and bone. ${ }^{16,39}$ Aberrant strain profiles have been implicated in the pathogenesis of a number of diseases affecting these tissues, including atherosclerosis. ${ }^{28,38}$ At the cellular level, strain applied via the extracellular matrix has been shown to elicit numerous responses including proliferation, altered gene expression, and cytoskeletal reorganization. ${ }^{14,24,25,35,37}$ Despite the obvious importance of mechanical signals,

Address correspondence to David J. Mooney, PhD, Department of Biologic and Materials Sciences, University of Michigan, School of Dentistry, 1011 N. University Avenue, Ann Arbor, MI 48109. Electronic mail: mooneyd@umich.edu relatively little is understood about the mechanism(s) mediating the transduction of mechanical information into the cell.

Focal adhesions are likely a major route for the transduction of mechanical signals. It has been well established that in two-dimensional culture cells are mechanically integrated with their substrate via focal adhesions, and analogous structures, such as the dense plaques of smooth muscle, are known to exist in vivo. ${ }^{5}$ Focal adhesions, or focal contacts, are the strongest and closest sites of adhesion between a cell and its substrate and are composed of clustered transmembrane integrin receptors and associated cytoskeletal and signaling molecules at the cytoplasmic face. ${ }^{5}$ By providing a continuous mechanical linkage between the extracellular matrix (ECM) and the cytoskeleton, as well as serving as centers of cellular signaling, focal contacts are ideally suited to serve as mechanosensors. Integrin binding to ECM proteins and the clustering of integrin receptors recruit a host of cytoskeletal proteins to the nascent focal contact, including the cross-linking protein vinculin and the actinbundling protein $\alpha$-actinin. ${ }^{4,21}$ Through a series of protein-protein interactions, these and other structural components physically interconnect the integrin cytoplasmic tails with the actin cytoskeleton. Also present at an early stage of focal contact assembly are the tyrosine kinase focal adhesion kinase (FAK) and one of its substrates, the more abundant paxillin, which have been implicated in the origin of intracellular chemical signals from focal contacts. ${ }^{22}$

Vinculin was one of the first focal contact components to be characterized and may play a key role in stabilizing adhesions. $^{11,30}$ Overexpression of vinculin results in large, stable focal contacts and relatively immobile cells, whereas disruption of vinculin expression produces smaller adhesions and highly motile cells. ${ }^{26,27}$ Conversely, pharmacologic agents that act to alter cellular contractility alter vinculin localization. Disruption of actinomyosin-generated tension causes focal contacts (as measured by vinculin distribution) to decrease in size, 
whereas increasing cellular contractility results in larger adhesions. $^{3,8,9}$

We hypothesize that externally applied mechanical stimuli, such as strain applied to cells via their adhesion substrate, regulate the localization of focal contact components. Few studies have addressed the effect of externally applied strain on focal contacts, and previous studies have focused primarily on relatively long-term (days) strain application. We have conducted studies in cultured smooth muscle cells to determine if the distribution of focal contact components is altered following short-term (minutes) application of mechanical strain to cells cultured on flexible silicone substrates. We have tested the simplest type of strain, a single step increase in strain, as well as the more complex but physiologically relevant condition of cyclic strain. Aortic smooth muscle cells were used in these studies because of the clear relevance of mechanical strain and the similarity of focal adhesions to native dense plaques. We have chosen to focus on several of the more abundant proteins as representative structural (vinculin, $\alpha$-actinin) and signaling (paxillin) components. Although previous studies found very significant long-term changes in focal contact-associated vinculin in response to strain, ${ }^{19,20}$ we anticipated that the short-term responses immediately following strain application might be quite subtle and possibly difficult to detect, particularly given the relatively large degree of uncertainty associated with current methods of quantifying cellular proteins. Based on that assumption, we designed the studies with multiple experiments and many replicates in order to capture the underlying trends. In order to begin elucidating the mechanism behind straininduced focal contact changes, we also conducted studies in permeabilized cells where the function of soluble signaling intermediates is likely to be disrupted. Rhodamine-labeled vinculin protein was added to permeabilized cells and its incorporation into focal adhesions, both with and without strain, was monitored microscopically.

\section{MATERIALS AND METHODS}

\section{Smooth Muscle Cell Isolation and Culture}

Smooth muscle cells were obtained from primary isolations of rat aorta using a previously published technique. ${ }^{29}$ Briefly, the descending aortas of male Lewis rats were dissected free and placed on ice. Surrounding fat and connective tissue were removed and the artery was cut longitudinally. The interior surface was scraped lightly with a scalpel and rinsed with phosphate buffered saline [(PBS), Gibco/Life Technologies, Gaithersburg, $\mathrm{MD}$ ] to remove the endothelium. The tissue was then minced and placed in enzymatic digestion buffer with gentle agitation at $37^{\circ} \mathrm{C}$. Enzymatic digestion buffer is $0.125 \mathrm{mg} / \mathrm{ml}$ elastase (Sigma Chemical Co., St. Louis,
MO), $1.0 \mathrm{mg} / \mathrm{ml}$ collagenase (CLS type I, 204 units/mg, Worthington Biochemical Corp., Freehold, NJ), 0.250 $\mathrm{mg} / \mathrm{ml}$ soybean trypsin inhibitor (type 1-S, Sigma), and $2.0 \mathrm{mg} / \mathrm{ml}$ bovine serum albumin [(BSA), Gibco]. The digested suspension was then filtered through a $100 \mu \mathrm{m}$ Nitex Filter (Tetko, Inc., Briarcliff Manor, NY) and centrifuged at $200 \mathrm{~g}$ for $5 \mathrm{~min}$. The pellet was resuspended in Medium 199 (Gibco) supplemented with 20\% fetal bovine serum [(FBS), Gibco], penicillin (100 units/ml, Gibco), and streptomycin $(0.1 \mathrm{mg} / \mathrm{ml}$, Gibco). After the first passage, the cells were maintained in Medium 199 containing $10 \%$ FBS and cultured according to standard techniques. Cells up to passage 20 were used for experiments.

\section{Strain Application}

BioFlex 6 well culture dishes with deformable silicone rubber bottom surfaces (Flexcell Int., Hillsborough, NC) were used to apply strain to cultured cells. The plates were passively coated with extracellular matrix at twice the theoretical saturating density of $1 \mu \mathrm{g} / \mathrm{cm}^{2}$ using the carbonate buffer method. ${ }^{13}$ Briefly, plates were exposed overnight to UV radiation from the sterilization bulb in a standard cell culture hood in order to activate the surface. Collagen type I (Vitrogen 100, $3 \mathrm{mg} / \mathrm{ml}$, Cohesion, Palo Alto, CA) was solubilized in carbonate buffer $\left(15 \mathrm{mM} \mathrm{Na} \mathrm{CO}_{3}, 35 \mathrm{mM} \mathrm{NaHCO}\right.$, pH to 9.4 with glacial acetic acid, reagents from Sigma) and incubated overnight on the surface to be coated. The plates were then rinsed twice with PBS before seeding them with cells.

Smooth muscle cells of passages 5-20 were seeded onto the collagen-coated BioFlex culture dishes at a density of $40,000-60,000$ cells $/ \mathrm{cm}^{2}$ in M199. Cells were allowed to adhere and spread for $24 \mathrm{~h}$, and were serum starved for 6-12 h prior to beginning the experiment in order to promote quiescence. For cyclic strain studies, strain was applied using the Flexercell strain unit (Flexcell Int.) connected to house vacuum. Cells were strained at a magnitude empirically verified to be $7 \%$ over $80 \%$ of the culture surface, at a frequency of $0.25 \mathrm{~Hz}(2 \mathrm{~s}$ strain, 2 s relaxation). In order to apply single step increases in strain, a custom-built apparatus previously described was used. ${ }^{24}$ Cells were strained by approximately $10 \%$. Three to five wells were designated for protein extraction, with the remaining wells reserved for cell counts.

Although the flex membranes produce an equibiaxial strain profile over most of the membrane surface, the outer $20 \%$ of the membrane experiences a very different strain profile. ${ }^{12,36}$ To avoid the confounding responses of cells in this region, cell seeding was restricted to the center of the membrane by means of PVC cylinder "fences." The fences were constructed from 1 in. ID Sch 
40 PVC pipe cut to a length of $3 / 4$ in., slightly higher than the depth of each well. The fences were sterilized by immersion in $70 \%$ ethanol and were then placed and centered in each BioFlex well. Holes $1 \mathrm{~cm}$ in diameter centered on each well were drilled in the culture dish lids to allow access for fluid changes. The lids were placed on the dishes and held tightly in place with two rubber bands, forcing the fences against the membrane to create a tight seal. After coating with ECM and cell seeding, but before strain application, the fences were removed.

\section{Immunofluorescence Staining and Microscopy}

Cells were permeabilized, fixed, and stained in order to visualize the cellular distribution of vinculin before and after various regimens of strain. The usual sequence of fixing and then permeabilizing was reversed in order to wash out soluble cytoplasmic vinculin, which obscures focal contact staining. Cells in 6 well BioFlex culture dishes were washed twice with ice cold PBS, permeabilized for one minute with $1 \mathrm{ml}$ of permeabilization buffer [10 mM N- 2- hydroxyethylpiperazine- $\mathrm{N}^{\prime}$-2-ethanesulfonic acid (HEPES) $\mathrm{pH}$ 6.9, $50 \mathrm{mM} \mathrm{NaCl}, 3 \mathrm{mM}$ $\mathrm{MgCl}_{2}$, and $300 \mathrm{mM}$ sucrose plus $1 \mathrm{mM}$ EGTA; all reagents from Sigma] with $0.5 \%$ Triton $\mathrm{X}-100,{ }^{2,18}$ and then rinsed for $30 \mathrm{~s}$ with another $1 \mathrm{ml}$ of permeabilization buffer. Cells were then fixed with $1 \mathrm{ml}$ of $4 \%$ formaldehyde in cytoskeleton buffer with sucrose $(10 \mathrm{mM}$ MES, pH 6.1, $138 \mathrm{mM} \mathrm{KCl,} 3 \mathrm{mM} \mathrm{MgCl}_{2}, 2 \mathrm{mM}$ EGTA, $0.32 \mathrm{M}$ sucrose). After several rinses in trisbuffered saline $(0.15 \mathrm{M} \mathrm{NaCl}, 0.02 \mathrm{M}$ tris- $\mathrm{HCl} \mathrm{pH} \mathrm{7.4)}$ with $0.1 \%$ Triton $\mathrm{X}-100$ (TBST) nonspecific binding was blocked for 10 min with antibody diluting solution [AbDil, 2\% bovine serum albumin (Gibco) in TBST]. Primary and secondary antibody incubations were for $1 \mathrm{~h}$ at room temperature in AbDil. Antihuman vinculin was obtained from Chemicon (Temecula, CA) and rhodaminelabeled antimouse secondary was from Jackson ImmunoResearch (West Grove, PA).

Stained cells were visualized on a Nikon E800 research microscope equipped with epifluorescence. Images were captured from the E800 with a DEI-470 camera (Optronics Engineering, Goleta, CA) and frame grabber board (Scion, Las Vegas, NV).

\section{Extraction of Insoluble and Total Cytoskeletal Fractions from Cultured Cells}

Cell extracts containing detergent-insoluble proteins (insoluble) and total cellular protein (total) were isolated at various time points before and after strain. In each experiment, all conditions contained a sample number of 3-5. In order to isolate insoluble proteins, cells were washed once in PBS, and once in permeabilization buffer (same as above) without detergent. Cells were then permeabilized in $1 \mathrm{ml}$ permeabilization buffer with $0.1 \%$
Triton X-100 (Sigma) and protease inhibitors $(10 \mu \mathrm{g} / \mathrm{ml}$ aprotinin, $10 \mu \mathrm{g} / \mathrm{ml}$ leupeptin, $5 \mu \mathrm{g} / \mathrm{ml}$ pepstatin A, 0.5 $\mathrm{mM}$ PMSF, all from Sigma) for $10 \mathrm{~min}$. After a $5 \mathrm{~min}$ wash in the same buffer, the remaining protein was solu-

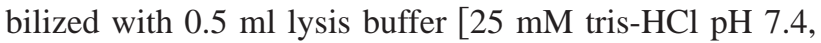
$0.4 \mathrm{M} \mathrm{NaCl}$, and $0.5 \%$ sodium dodecyl sulfate (Ref. 6)] with protease inhibitors for $5 \mathrm{~min}$. The culture wells were scraped with a rubber policeman and the cell lysate was transferred to a microcentrifuge tube and frozen at $-70{ }^{\circ} \mathrm{C}$ until analysis. Total cellular protein was obtained by incubating whole cells from parallel samples directly with lysis buffer after four washes in PBS.

\section{Western Blotting}

Focal contact proteins in cell extracts were analyzed by standard western blotting techniques. Gel loading was normalized to total protein in each extract as determined by the Pierce BCA Assay (Pierce, Rockford, IL), with 40-60 $\mu \mathrm{g}$ of protein loaded per lane. Electrophoresis was performed in $10 \%$ SDS polyacrylamide gels according to standard methods. ${ }^{15}$ Proteins were transferred to PVDF membrane (Bio-Rad Laboratories, Hercules, CA) and blocked with $1 \%-5 \%$ BSA in tris-buffered saline

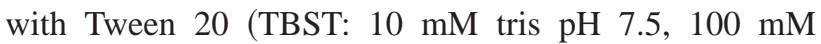
$\mathrm{NaCl}, 0.1 \%$ Tween 20, Sigma) overnight at $4{ }^{\circ} \mathrm{C}$.

Membranes were incubated with primary antibody diluted in blocking buffer for $1 \mathrm{~h}$ at room temperature with agitation. After washing in TBST, membranes were incubated for $1 \mathrm{~h}$ with HRP-conjugated goat antimouse IgG (Bio-Rad) diluted to 1:1000 in TBST. After several more washes, proteins were detected using enhanced chemiluminescence [(ECL), Amersham Pharmacia Biotech, Piscataway, NJ] and recorded on Hyperfilm ECL (Amersham). Films were developed and fixed using GBX reagents (Kodak, Rochester, NY). Developed films were scanned and subjected to densitometry using NIH Image. Monoclonal mouse antihuman alpha actinin (Chemicon), monoclonal mouse antipaxillin (Transduction Laboratories, Lexington, KY), and monoclonal mouse antiphosphotyrosine, clone PY-20 (Transduction Laboratories) were obtained commercially. Statistical analysis was performed with InStat Software (GraphPad Software). The Student's t-test was used to determine statistical significance.

\section{Incorporation of Rhodamine-Labeled Vinculin into Permeabilized Cells}

Vinculin protein standard (American Research Products, Belmont, MA) was labeled with lissamine rhodamine B sulfonyl chloride (Molecular Probes, Eugene, OR) according to a previously published technique. ${ }^{1}$ The vinculin protein standard is formulated in a tris buffer, and so requires dialysis to remove the tris salts to prevent their undesired reaction with the 
rhodamine. One milligram of vinculin protein was dialyzed at $4{ }^{\circ} \mathrm{C}$ for $8 \mathrm{~h}$ against a $0.2 \mathrm{M}$ sodium carbonate buffer $(\mathrm{pH}$ 8.5) in a Spectra/Por CE DispoDialyzer (MWCO 1000, $1 \mathrm{ml}$ volume, Spectrum Laboratories, Rancho Dominguez, CA). After dialysis the protein was reacted with a tenfold molar excess of rhodamine [stock solution of $10 \mathrm{mg} / \mathrm{ml}$ prepared in dimethyl formamide (DMF, Sigma)] for $1 \mathrm{~h}$ at $4{ }^{\circ} \mathrm{C}$ with gentle rocking. The labeled protein was then separated from unreacted rhodamine on a Sephadex column (PD-10, Amersham Pharmacia Biotech). The molar labeling ratio (label/ protein) was 0.284 . The purified protein was aliquotted and stored at $-70{ }^{\circ} \mathrm{C}$.

Binding of rhodamine-labeled vinculin to permeabilized SMC was carried out according to a previously published technique. ${ }^{2}$ Briefly, cells were rinsed in cold PBS, then permeabilized for $30 \mathrm{~s}$ in permeabilization buffer containing $0.5 \%$ Triton X-100. The cells were then rinsed twice with cold binding buffer $(25 \mathrm{mM}$ MES, $\mathrm{pH}$ 6.0, $3 \mathrm{mM} \mathrm{MgCl}$, $1 \mathrm{mM}$ EGTA), followed by incubation with rhodamine vinculin in binding buffer (10 $\mu \mathrm{g} / \mathrm{ml}$ ) for $15 \mathrm{~min}$ on ice. Strain was also applied during this time. Cells were rinsed twice more with cold binding buffer, and then fixed for 20 min with $3 \%$ formaldehyde in PBS.

\section{RESULTS}

\section{Microscopic Evaluation of Focal Contact-Associated Vinculin Levels With Strain}

In order to grossly determine whether strain induces changes in focal contact-associated vinculin levels, cells were subjected to either a $10 \%$ step increase in strain or a $7 \%, 0.25 \mathrm{~Hz}$ cyclic strain for varying lengths of time. Cells were then stained using standard immunofluorescence techniques and viewed under a microscope. A $10 \%$ step increase in strain induced no apparent change in focal contact vinculin staining at $1,5,15,30$, or 60 min following strain (data not shown). In contrast, cyclic strain induced a slight increase in focal contact vinculin relative to unstrained cells (Fig. 1). Significant variability in vinculin staining was observed between cells. Because of this fact and the technical complexity of analyzing small, numerous structures such as focal contacts by standard imaging techniques, changes in vinculin distribution were subsequently quantified by western blotting.

\section{Biochemical Quantification of Insoluble Vinculin Levels Following a Step Increase in Strain}

Strain-induced changes in focal contact components were quantified at the cell population level by standard biochemical methods. It must be noted that these methods do not discriminate between focal contact-associated proteins and insoluble adhesion proteins associated with
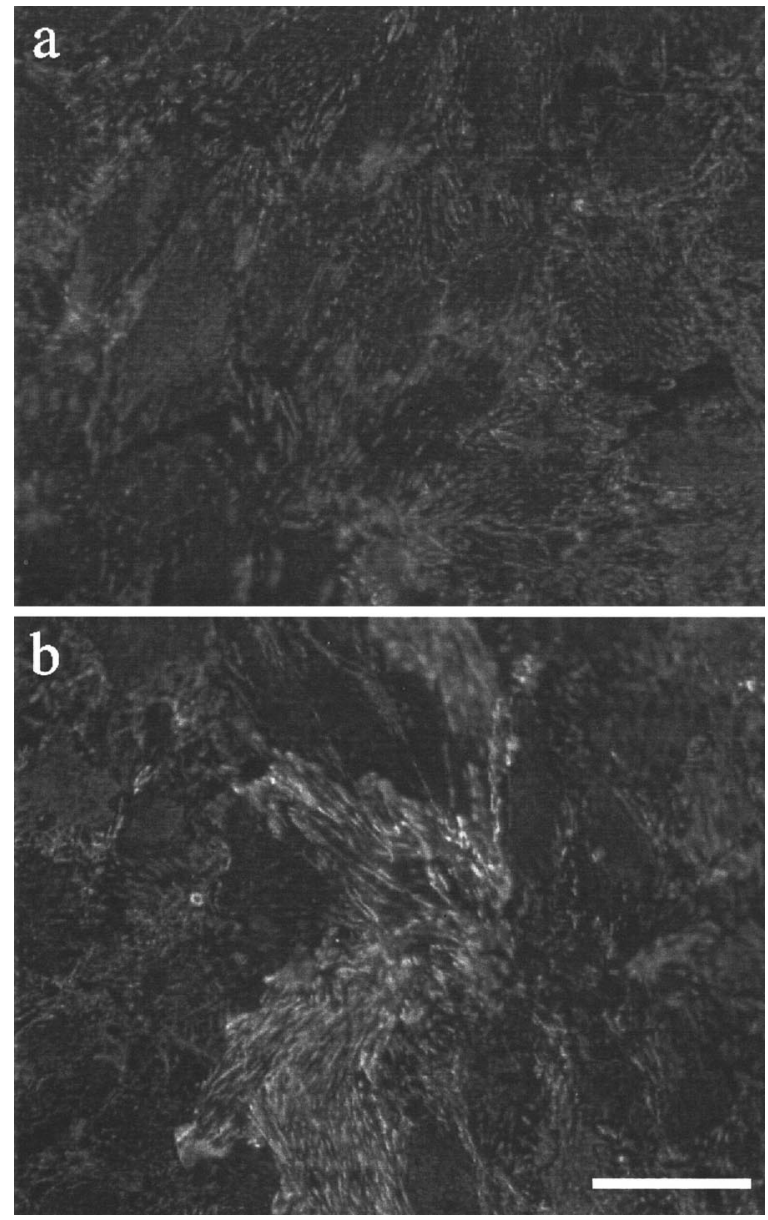

FIGURE 1. Vinculin immunofluorescence micrographs of rat aortic smooth muscle cells cultured on BioFlex dishes. Cells were permeabilized, fixed, and stained $25 \mathrm{~min}$ after initiation of strain. (a) Cells maintained in static culture. (b) Cells subjected to a $7 \%, 0.25 \mathrm{~Hz}$ cyclic strain using the Flexercell strain device. A subtle, but consistent, increase in the overall intensity of vinculin staining was noted in the strained cells compared to control. Size bar is $50 \mu \mathrm{m}$.

other cellular structures (i.e., cell-cell adhesions). However, immunofluorescence microscopy suggests that, in our cells, the vast majority of insoluble vinculin and paxillin is present in cell-matrix adhesions. A single $10 \%$ step increase in substrate strain was applied to cells grown in 6 well BioFlex dishes and focal contactassociated vinculin was quantified. Five independent experiments covering various time points were conducted to compensate for variability. Combining the data from all five experiments [Fig. 2(a)] revealed a small but statistically significant decrease in focal contact-associated vinculin at $30 \mathrm{~min}$ following strain. Due to the short time course investigated in this study, protein synthesis and degradation were not expected to play a role in the observed responses. This was verified in a separate experiment by measuring total cellular vinculin at various time points, which showed no change compared to the levels 

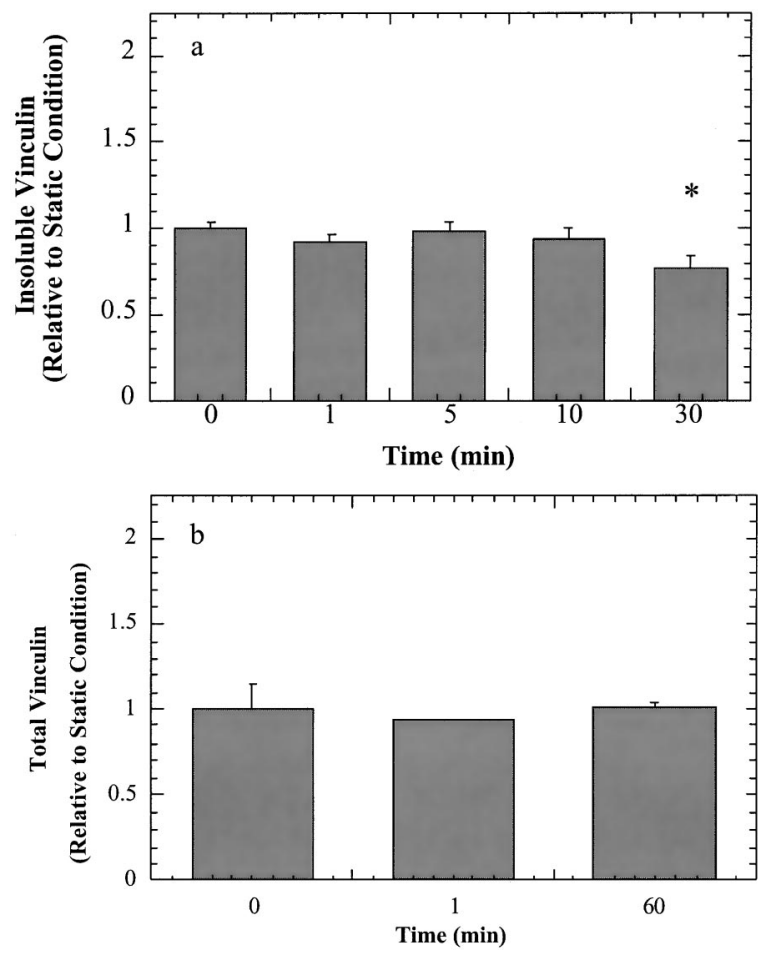

FIGURE 2. Biochemical quantification of focal contactassociated vinculin in smooth muscle cells subjected to a $10 \%$ step increase in strain. Insoluble vinculin was assayed as a function of time by quantitative western blotting. (a) Results from five independent experiments, each containing five independent samples, were combined and plotted together (mean \pm SEM). A small but statistically significant decrease in insoluble vinculin was noted at $30 \mathrm{~min}$ $(* p<0.05$ compared to $t=0)$. (b) Total cellular vinculin in a representative experiment. There is no statistically significant change in total vinculin even after $1 \mathrm{~h}$ of strain, confirming that protein synthesis and degradation do not play a role in vinculin dynamics during this short time course.

in unstrained cells [Fig. 2(b)]. To verify that the lack of response was not due simply to the magnitude of strain tested, insoluble vinculin was quantified after step applications of other magnitudes of strain. There was no significant change in insoluble vinculin with any magnitude tested, ranging from 5\% to 20\% (data not shown).

\section{Cyclic Strain Alters Insoluble Levels of Structural and Signaling Components}

Although single step strains are the simplest to study and are useful for experiments addressing mechanism, cyclic strain has much more physiological relevance to vascular smooth muscle. After application of a 7\% strain at a frequency of $0.25 \mathrm{~Hz}$ for varying lengths of time, cell proteins were extracted and analyzed for vinculin by quantitative western blotting. In seven independent experiments, focal contact-associated vinculin was found to increase overall by $52 \%$ within 1 min of strain $(p$ $<0.05$ ) but then returned to lower levels by $1 \mathrm{~h}$ (Fig. 3).

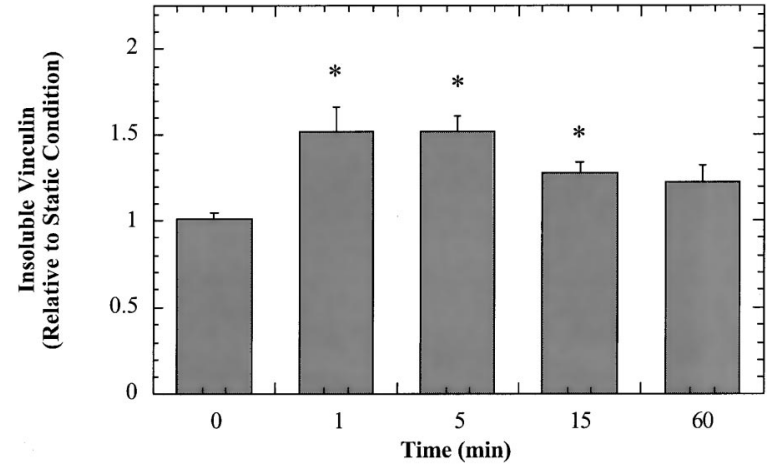

FIGURE 3. Biochemical quantification of focal contactassociated vinculin with $7 \%$ cyclic strain at a frequency of $0.25 \mathrm{~Hz}$. The results of seven independent experiments, each containing five independent samples, were combined and plotted together (mean \pm SEM). A much larger enrichment of vinculin was noted as compared to a single step strain, followed by a return to lower levels within $1 \mathrm{~h}$. This may reflect a reorganization of cell adhesions as the cells adapt to their new mechanical environment $(* p<0.05$ compared to $t=0)$.

Once again, in order to verify that the increase in insoluble vinculin is due to incorporation from the soluble cytoplasmic pool and not due to new synthesis, total vinculin was also measured and found to remain constant over the time course studied (data not shown).

We next quantified focal contact-associated paxillin following cyclic strain application. Focal contactassociated paxillin increased in a similar manner, although it increased by a much larger magnitude than noted for vinculin [Fig. 4(a)]. In order to ensure that the observed responses reflected actual changes, and were not just an artifact of the experimental methods, we also quantified insoluble $\alpha$-actinin, which we did not expect to change with strain. Any strain-induced changes in focal contact $\alpha$-actinin would likely be small, and therefore difficult to detect, relative to the large amounts incorporated in actin stress fibers. As expected, insoluble $\alpha$-actinin showed no statistically significant increase over the time course investigated [Fig. 4(b)].

\section{Strain-induced Incorporation of Rhodamine-labeled Vinculin into Permeabilized SMC}

To test whether soluble signaling intermediates are necessary for the observed enrichment of insoluble vinculin with cyclic strain, incorporation of rhodaminelabeled vinculin into the cytoskeleton of permeabilized cells was monitored microscopically. Smooth muscle cells were permeabilized by a brief detergent extraction and exposed to rhodamine-labeled vinculin at a concentration of $10 \mu \mathrm{g} / \mathrm{ml}$. A base-line incorporation of labeled vinculin into the focal contacts of permeabilized cells was observed in static culture after 15 min of incubation [Fig. 5(a)]. Application of 7\%, $0.25 \mathrm{~Hz}$ cyclic strain during this time significantly enhanced the incorporation 

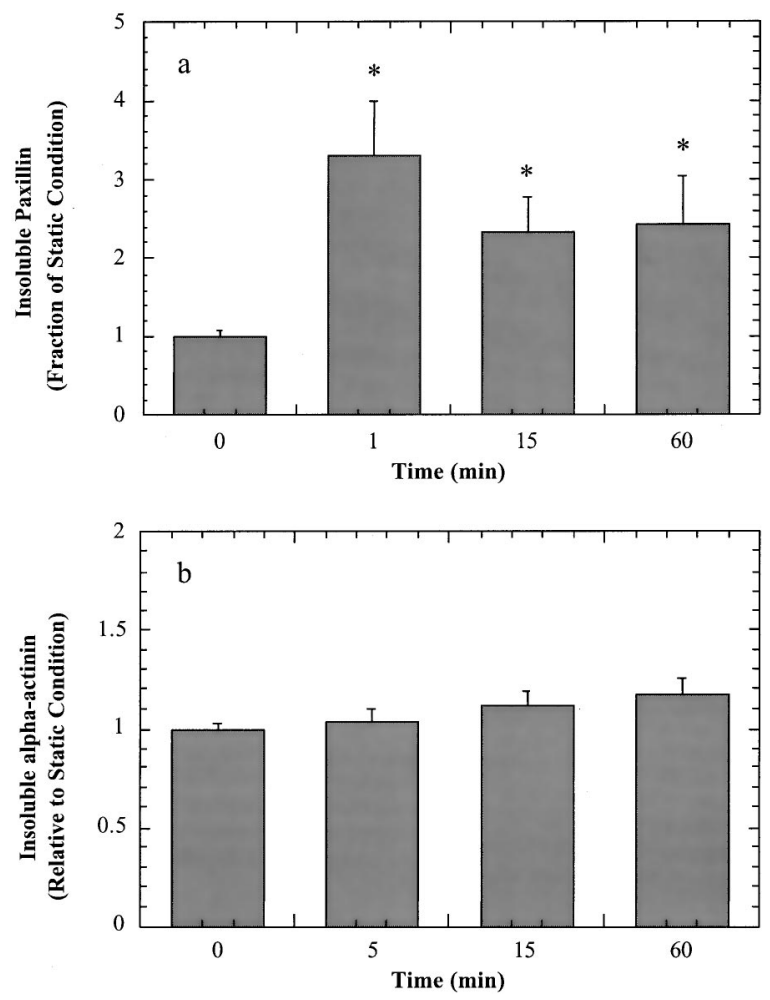

FIGURE 4. Focal contact-associated paxillin and $\alpha$-actinin levels during cyclic strain relative to levels in unstrained cells. (a) Cyclic strain induces a large increase in insoluble, focal contact associated paxillin as detected by western blotting with a monoclonal antibody. Data shown are averaged results from two separate experiments ( $n=6$ for each, mean \pm SEM) $(* p<0.05$ compared to $t=0)$. (b) Insoluble $\alpha$-actinin over time during application of $7 \%, 0.25 \mathrm{~Hz}$ cyclic strain. Results shown are combined data from two independent experiments $(n=6$ for each, mean \pm SEM). There is no statistically significant change in insoluble $\alpha$-actinin over the time course investigated.

of labeled vinculin into both focal contacts and cell-cell adhesions as revealed by fluorescence microscopy [Fig. 5(b)]. In contrast to cyclic strain, but in agreement with previous findings, a single step increase in strain did not cause any observable change in vinculin amounts associated with either focal contacts or cell-cell contacts [Fig. 5(c)].

\section{DISCUSSION}

The goal of this study was to determine whether externally applied mechanical strain produces changes in the subcellular distribution of focal contact components in cultured smooth muscle cells. Previous attempts to address this question have investigated widely different strain regimes, time frames, and cell types. In order to begin elucidating the mechanism of force transduction through focal contacts, we have chosen to examine shortterm changes using a combination of fluorescence microscopy and quantitative measurement of focal contact
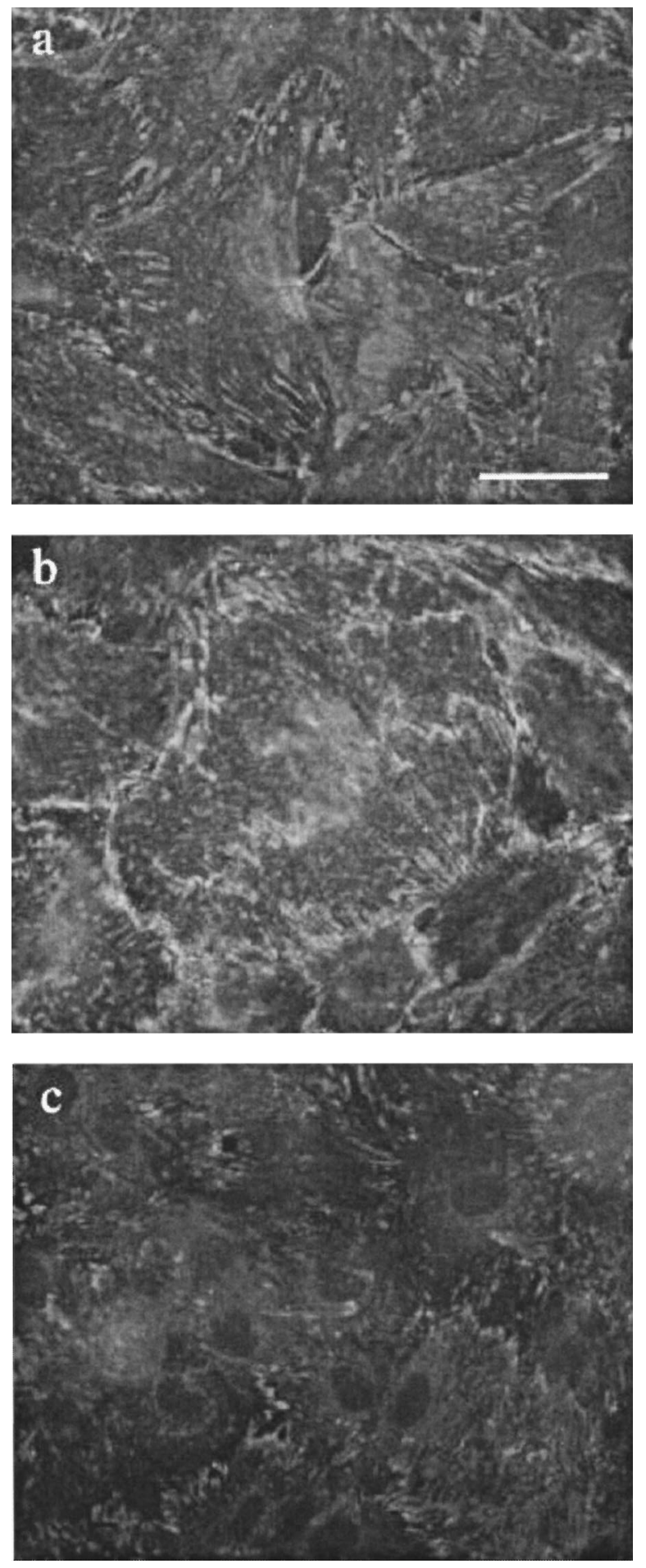

FIGURE 5. Fluorescence micrographs of permeabilized SMCs to which rhodamine-labeled vinculin was added at a concentration of $10 \mu \mathrm{g} / \mathrm{ml}$. The permeabilized cells were incubated for 15 min with the labeled vinculin, during which time they were either (a) left in static culture; (b) strained cyclically at $7 \%, 0.25 \mathrm{~Hz}$; or (c) subjected to a $10 \%$ step increase in strain. Insoluble vinculin levels increased significantly compared to unstrained controls with cyclic strain but not a single step increase in strain. Size bar is $50 \mu \mathrm{m}$. 
components by western blotting with large sample numbers and multiple experiments. For these studies, we chose to focus on three relatively abundant proteins that are representative of the structural and signaling components of focal adhesions, namely, vinculin, $\alpha$-actinin, and paxillin. Studies conducted in our laboratory revealed that other components, including FAK, talin, and tensin, are present in relatively small amounts in our cell system (data not shown), making quantitative analysis of these components more difficult. We focused particularly on vinculin, because of its abundance in focal contacts, its physiological importance to cell adhesion, and the commercial availability of the purified protein..$^{10,26,27}$

The major finding presented here is that application of cyclic strain, but not an individual step increase in strain, is sufficient to cause substantial enrichment of vinculin in focal contacts. Cyclic strain also induces enrichment in paxillin of even greater magnitude, but no enrichment in $\alpha$-actinin. These results are consistent with earlier studies in the literature, although it is difficult to make direct comparisons because of differences in cell type and strain magnitudes, frequencies, and duration. It has previously been reported that focal contact-associated vinculin in osteoblasts may increase or decrease depending on the type and duration of strain. ${ }^{19,20}$ Pharmacologic unloading of cardiac myocytes induces a depletion of cellular vinculin, which is reversed by application of static strain. ${ }^{33}$ Cells cultured on pliant substrates have been shown to contain smaller, less stable adhesions than cells cultured on rigid substrates, ${ }^{23}$ and cells have been observed to strengthen their adhesion in response to tension. ${ }^{7}$ It has also been reported that mechanical strain induces increased tyrosine phosphorylation of specific focal contact components, including FAK and paxillin. ${ }^{31,32,34,40}$ The results we have presented here complement and extend these past findings by providing information at earlier time points, which will be crucial in elucidating the mechanism of focal contact-mediated force transduction. Additional insight and relevance to previous studies will be gained by extending these studies to a wider range of cyclic strain frequencies, magnitudes, and durations, as well as by conducting studies addressing the dynamics of other focal contact components, such as FAK.

The incorporation of vinculin and paxillin into focal adhesions may be physiologically important. Vinculin, as a ubiquitous cross-linking element within focal adhesions, appears to impart stability to adhesions and may play a role in strengthening adhesion. ${ }^{10}$ It is reasonable to expect that cells might strengthen their adhesion (or subsets of adhesions) to the substratum when placed in a mechanically dynamic environment. The recruitment of paxillin may serve to enhance the generation of soluble second messenger signals from focal adhesions. Measurement of $\alpha$-actinin provides an appropriate negative control on the methods since one would not expect significant changes in insoluble $\alpha$-actinin due to the large (presumably unchanging) amounts of the protein associated with the actin cytoskeleton. ${ }^{17}$ While we do suspect that focal contact-associated $\alpha$-actinin levels change, a more discriminating method of isolating focal contact components would be necessary to observe this change.

An important result of these studies is the finding that a certain number of mechanical perturbations are required in order to significantly activate the enrichment of vinculin in focal contacts. This number of perturbations is less than 15 cycles, since enrichment was observed after just $1 \mathrm{~min}$ of $0.25 \mathrm{~Hz}$ cyclic strain, but greater than a single step. One possible explanation is that breakage of adhesions by the initial cycle of strain may decrease the net recruitment of vinculin due to that cycle. Only on subsequent cycles, after the weakest contacts or those not favored by the applied regimen of strain have broken, is substantial enrichment observed. Further microscopy studies are needed to investigate this possibility. We envision two general (nonexclusive) classes of mechanism that could account for vinculin recruitment with multiple cycles of strain. The first involves strain-dependent activation of some chemical second messenger species after the threshold number of cycles, possibly mediated by paxillin phosphorylation, which then mediates enrichment in vinculin. In this model, the transient nature of the vinculin and paxillin enrichment could reflect a subsequent deactivation of the signaling pathway, possibly as a result of reorganization of the cell's adhesions in response to the mechanically active environment. The second class of mechanism is purely mechanical in nature, involving conformational changes in focal contact proteins caused directly by the mechanical strain placed on those proteins. This could expose additional binding sites for recruitment of components from the soluble cytoplasmic pool. Such a mechanism has already been demonstrated to be involved in fibronectin matrix assembly. ${ }^{41}$

In order to begin discriminating between these possibilities, we conducted a strain experiment with permeabilized cells to which fluorescently labeled vinculin was added. Permeabilization was performed prior to initiation of any mechanical signal and is sufficient to wash away soluble cellular components such as diffusible second messenger molecules. Our results are consistent with the possibility that new binding sites for vinculin are exposed by mechanical strain. Specifically, microscopy revealed that cyclic strain significantly increased the amount of labeled vinculin incorporated into both the focal contacts and cell-cell contacts compared to both unstrained cells and cells exposed to a single step increase in strain. This is in agreement with our findings from immunofluorescence of whole cells and supports the theory that at least one component of the mechanism 
behind these observations is independent of soluble signaling intermediates and may be purely mechanical in nature. Additional experiments in which the frequency, magnitude, and duration of strain are varied will provide further insight into the mechanism responsible for these observations.

In summary, these studies indicate that multiple mechanical perturbations significantly and rapidly alter focal contact-associated vinculin and paxillin levels, mediated at least in part by a mechanism that is not dependent on the diffusion of chemical signaling intermediates. Additional microscopy studies will further complete the picture by revealing the extent of adhesion breakage, formation, and reorganization that occur during and after strain. These studies and others will contribute to a greater understanding of how cells sense and respond to their mechanical environment.

\section{ACKNOWLEDGMENTS}

Financial support from the University of Michigan Cellular Biotechnology Training Program (NIH Grant No. GM08353), the University of Michigan Center for Biomedical Engineering Research, and the National Institutes of Health (NIH Grant No. RO1 DE13349) is gratefully acknowledged.

\section{REFERENCES}

${ }^{1}$ Avnur, Z., J. V. Small, and B. Geiger. Actin-independent association of vinculin with the cytoplasmic aspect of the plasma membrane in cell-contact areas. J. Cell Biol. 96:1622-1630, 1983.

${ }^{2}$ Ball, E. H., H. C. Freitag, and S. Gurofsky. Vinculin interaction with permeabilized cells: Disruption and reconstitution of a binding site. J. Cell Biol. 103:641-648, 1986.

${ }^{3}$ Bershadsky, A., A. Chausovsky, E. Becker, A. Lyubimova, and B. Geiger. Involvement of microtubules in the control of adhesion-dependent signal transduction. Curr. Biol. 6:12791289, 1996.

${ }^{4}$ Burridge, K., and M. Chrzanowska-Wodnicka. Focal adhesions, contractility, and signaling. Annu. Rev. Cell Dev. Biol. 12:463-518, 1996.

${ }^{5}$ Burridge, K., K. Fath, T. Kelly, G. Nuckolls, and C. Turner. Focal adhesions: Transmembrane junctions between the extracellular matrix and the cytoskeleton. Annu. Rev. Cell Biol. 4:487-525, 1988.

${ }^{6}$ Caron, J. M., A. L. Jones, and M. W. Kirschner. Autoregulation of tubulin synthesis in hepatocytes and fibroblasts. $J$. Cell Biol. 101:1763-1772, 1985.

${ }^{7}$ Choquet, D., D. P. Felsenfeld, and M. P. Sheetz. Extracellular matrix rigidity causes strengthening of integrin-cytoskeleton linkages. Cell 88:39-48, 1997.

${ }^{8}$ Chrzanowska-Wodnicka, M., and K. Burridge. Rhostimulated contractility drives the formation of stress fibers and focal adhesions. J. Cell Biol. 133:1403-1415, 1996.

${ }^{9}$ Danowksi, B. A. Fibroblast contractility and actin organization are stimulated by microtubule inhibitors. J. Cell. Sci. 93:255-266, 1989.
${ }^{10}$ Ezzell, R. M., W. H. Goldmann, N. Wang, N. Parasharama, and D. E. Ingber. Vinculin promotes cell spreading by mechanically coupling integrins to the cytoskeleton. Exp. Cell Res. 231:14-26, 1997.

${ }^{11}$ Geiger, B. A $130 \mathrm{k}$ protein from chicken gizzard: Its localization at the termini of microfilament bundles in cultured chicken cells. Cell 18:193-205, 1979.

${ }^{12}$ Gilbert, J. A., P. S. Weinhold, A. J. Banes, G. W. Link, and G. L. Jones. Strain profiles for circular cell culture plates containing flexible surfaces employed to mechanically deform cells in vitro. J. Biomech. 27:1169-1177, 1994.

${ }^{13}$ Ingber, D. E. Fibronectin controls capillary endothelial cell growth by modulating cell shape. Proc. Natl. Acad. Sci. U.S.A. 87:3579-3583, 1990.

${ }^{14}$ Kim, B. S., J. Nikolovski, J. Bonadio, and D. J. Mooney. Cyclic mechanical strain regulates the development of engineered smooth muscle tissue. Nat. Biotechnol. 17:979-983, 1999.

${ }^{15}$ Laemmli, U. K. Cleavage of structural proteins during the assembly of the head of bacteriophage t4. Nature (London) 227:680-685, 1970 .

${ }^{16}$ Langille, B. L. Chronic effects of blood flow on the artery wall. In: Physical Forces and the Mammalian Cell, edited by J. Frangos. San Diego, CA: Academic, 1993.

${ }^{17}$ Lazarides, E., and K. Burridge. Alpha-actinin: Immunofluroescent localization of a muscle structural protein in nonmuscle cells. Cell 6:289-298, 1975.

${ }^{18}$ Lee, S. W., and J. J. Otto. Differences in turnover rates of vinculin and talin caused by viral transformation and cell density. Exp. Cell Res. 227:352-359, 1996.

${ }^{19}$ Meazzini, M. C., C. D. Toma, J. L. Schaffer, M. L. Gray, and L. C. Gerstenfeld. Osteoblast cytoskeletal modulation in response to mechanical strain in vivo. J. Orthop. Res. 16:170180, 1998.

${ }^{20}$ Meyer, U., T. Meyer, and D. B. Jones. No mechanical role for vinculin in strain transducation in primary bovine osteoblasts. Biochem. Cell Biol. 75:81-87, 1997.

${ }^{21}$ Miyamoto, S., S. K. Akiyama, and K. M. Yamada. Synergistic roles for receptor occupancy and aggregation in integrin transmembrane function. Science 267:883-885, 1995.

${ }^{22}$ Miyamoto, S., H. Teramoto, O. A. Coso, J. S. Gutkind, P. D. Burbelo, S. K. Akiyama, and K. M. Yamada. Integrin function: Molecular hierarchies of cytoskeletal and signaling molecules. J. Cell Biol. 131:791-805, 1995.

${ }^{23}$ Pelham, Jr. R. J., and Y. Wang. Cell locomotion and focal adhesions are regulated by substrate flexibility. Proc. Natl. Acad. Sci. U.S.A. 94:13661 13665, 1997.

${ }^{24}$ Putnam, A. J., J. J. Cunningham, R. G. Dennis, J. J. Linderman, and D. J. Mooney. Microtubule assembly is regulated by externally applied strain in cultured smooth muscle cells. J. Cell. Sci. 111:3379-3387, 1998.

${ }^{25}$ Reusch, P., H. Wagdy, R. Reusch, E. Wilson, and H. E. Ives. Mechanical strain increases smooth muscle and decreases nonmuscle myosin expression in rat vascular smooth muscle cells. Circ. Res. 79:1046-1053, 1996.

${ }^{26}$ Rodriguez Fernandez, J. L., B. Geiger, D. Salomon, and A. Ben-Ze'ev. Overexpression of vinculin suppresses cell motility in balb/c 3t3 cells. Cell Motil. Cytoskeleton 22:127-134, 1992.

${ }^{27}$ Rodriguez Fernandez, J. L., B. Geiger, D. Salomon, and A. Ben-Ze'ev. Suppression of vinculin expression by antisense transfection confers changes in cell morphology, motility, and anchorage-dependent growth of $3 \mathrm{t} 3$ cells. J. Cell Biol. 122:1285-1294, 1993.

${ }^{28}$ Ross, R. The pathogenesis of atherosclerosis: A perspective for the 1990s. Nature (London) 362:801-809, 1993. 
${ }^{29}$ Rothman, A., T. J. Kulik, M. B. Taubman, B. C. Berk, C. W. Smith, and B. Nadal-Ginard. Development and characterization of a cloned rat pulmonary arterial smooth muscle cell line that maintains differentiated properties through multiple subcultures. Circulation 86:1977-1986, 1992.

${ }^{30}$ Samuels, M., R. M. Ezzell, T. J. Cardozo, D. R. Critchley, J. L. Coll, and E. D. Adamson. Expression of chicken vinculin complements the adhesion-defective phenotype of a mutant mouse f9 embryonal carcinoma cell. J. Cell Biol. 121:909921, 1993.

${ }^{31}$ Schmidt, C., H. Pommerenke, F. Durr, B. Nebe, and J. Rychly. Mechanical stressing of integrin receptors induces enhanced tyrosine phosphorylation of cytoskeletally anchored proteins. J. Biol. Chem. 273:5081-5085, 1998.

${ }^{32}$ Seko, Y., N. Takahashi, K. Tobe, T. Kadowaki, and Y. Yazaki. Pulsatile stretch activates mitogen-activated protein kinase (mapk) family members and focal adhesion kinase [p125(fak)] in cultured rat cardiac myocytes. Biochem. Biophys. Res. Commun. 259:8-14, 1999.

${ }^{33}$ Sharp, W. W., D. G. Simpson, T. K. Borg, A. M. Samarel, and L. Terracio. Mechanical forces regulate focal adhesion and costamere assembly in cardiac myocytes. Am. J. Physiol. 273:H546-H556, 1997.

${ }^{34}$ Smith, P. G., R. Garcia, and L. Kogerman. Mechanical strain increases protein tyrosine phosphorylation in airway smooth muscle cells. Exp. Cell Res. 239:353-360, 1998.
${ }^{35}$ Smith, P. G., K. E. Janiga, and M. C. Bruce. Strain increases airway smooth muscle cell proliferation. Am. J. Respir. Cell Mol. Biol. 10:85-90, 1994.

${ }^{36}$ Sotoudeh, M., S. Jalali, S. Usami, J. Y. Shyy, and S. Chien. A strain device imposing dynamic and uniform equibiaxial strain to cultured cells. Ann. Biomed. Eng. 26:181-189, 1998; 26:735, 1998.

${ }^{37}$ Sumpio, B. E., A. J. Banes, L. G. Levin, and G. Johnson, Jr. Mechanical stress stimulates aortic endothelial cells to proliferate. J. Vasc. Surg. 6:252-256, 1987.

${ }^{38}$ Thubrikar, M. J., and F. Robicsek. Pressure-induced arterial wall stress and atherosclerosis. Ann. Thorac. Surg. 59:1594$1603,1995$.

${ }^{39}$ Wolff, J. Das Gesetz der Transformation der Knochen. Berlin: Hirchwild, 1892; Wolff, J. The Law of Bone Remodeling, translated by P. Maquet and R. Furlong. Berlin: Springer, 1986.

${ }^{40}$ Yano, Y., J. Geibel, and B. E. Sumpio. Tyrosine phosphorylation of pp125fak and paxillin in aortic endothelial cells induced by mechanical strain. Am. J. Physiol. 271:C635C649, 1996.

${ }^{41}$ Zhong, C., M. Chrzanowska-Wodnicka, J. Brown, A. Shaub, A. M. Belkin, and K. Burridge. Rho-mediated contractility exposes a cryptic site in fibronectin and induces fibronectin matrix assembly. J. Cell Biol. 141:539-551, 1998. 